\title{
Carbon-ion Radiotherapy for Inoperable Head and Neck Bone and Soft-tissue Sarcoma: Prospective Observational Study
}

\author{
ATSUSHI MUSHA ${ }^{1,2}$, NOBUTERU KUBO ${ }^{1}$, HIDEMASA KAWAMURA ${ }^{1}$, NAOKO OKANO $^{1}$, HIRO SATO $^{1}$, \\ KOHEI OKADA ${ }^{1}$, NAOTO OSU ${ }^{1}$, HIKARU YUMISAKI ${ }^{1}$, AKIKO ADACHI ${ }^{1}$, YUKIHIRO TAKAYASU ${ }^{3}$, \\ MASATO SHINO $^{3}$, OSAMU NIKKUNI ${ }^{3}$, SHOTA IDA ${ }^{3}$, KATSUYUKI SHIRAI ${ }^{1,4}$, JUN-ICHI SAITOH ${ }^{1,5}$, \\ SATOSHI YOKOO ${ }^{2}$, KAZUAKI CHIKAMATSU ${ }^{3}$ and TATSUYA OHNO ${ }^{1}$, \\ WORKING GROUP ON HEAD AND NECK TUMORS \\ ${ }^{1}$ Gunma University Heavy Ion Medical Center, Maebashi, Japan; \\ ${ }^{2}$ Department of Oral and Maxillofacial Surgery and Plastic Surgery, \\ Gunma University Graduate School of Medicine, Maebashi, Japan; \\ ${ }^{3}$ Department of Otolaryngology-Head and Neck Surgery, \\ Gunma University Graduate School of Medicine, Maebashi, Japan; \\ ${ }^{4}$ Department of Radiology, Jichi Medical University Hospital, Tochigi, Japan; \\ ${ }^{5}$ Division of Radiation Oncology, Department of Radiology, Faculty of Medicine, \\ Academic Assembly, University of Toyama, Toyama, Japan
}

\begin{abstract}
Background/Aim: Bone and soft-tissue sarcomas of the head and neck have very poor prognoses. This prospective study aimed to investigate the efficacy and safety of carbon-ion radiotherapy (C-ion $R T)$ for bone and softtissue sarcoma of the head and neck. Patients and Methods: The present study was a prospective clinical study that included 10 consecutive patients diagnosed with bone and soft-tissue sarcoma of the head and neck who were treated with C-ion RT between 2012 and 2018 at our institution. $C$ Ion $R T$ consisted of $70.4 \mathrm{~Gy}$ (relative biological effectiveness) in 16 fractions. Results: The 3-year local control, overall survival, and progression-free survival rates for patients overall were $72.9 \%$, $77.8 \%$, and $36 \%$, respectively. Conclusion: The present study demonstrated the efficacy of $C$-ion RT for bone and soft-tissue sarcoma of the head and neck; adverse events were within the expected range.
\end{abstract}

Correspondence to: Atsushi Musha, DDS, Ph.D., Gunma University Heavy Ion Medical Center, 3-39-22, Showa-machi, Maebashi, Gunma, 371-8511, Japan. Tel: +81 272208383, Fax: +81 272208397, e-mail: musha@gunma-u.ac.jp

Key Words: Bone and soft-tissue sarcoma, carbon-ion radiotherapy, head and neck tumor.

This article is an open access article distributed under the terms and conditions of the Creative Commons Attribution (CC BY-NC-ND) 4.0 international license (https://creativecommons.org/licenses/by-nc-nd/4.0)
Bone and soft-tissue sarcomas of the head and neck (BSSHN) account for less than $1 \%$ of all head and neck malignancies and less than $10 \%$ of all soft-tissue sarcomas (1). Treatment of BSS-HN varies depending on histological type but surgery is generally the mainstay of treatment. However, there are many cases in which resection or reconstruction is difficult because of functional or cosmetic challenges that affect the quality of life or due to the proximity of the tumor to the orbit or skull base. Therefore, radical surgery is combined with chemotherapy and radiotherapy to treat BSS-HN (2). BSSHN has a very poor prognosis, with a 5-year overall survival (OS) rate of 21.7-59.7\% with surgery, chemotherapy, and radiotherapy (2-4). Because BSS-HN is a rare tumor, there are few reports on it compared with those on squamous cell carcinomas, and a viable treatment method has yet to be established.

Carbon-ion radiotherapy (C-ion $\mathrm{RT}$ ) provides highly concentrated radiation dose distributions with a Bragg peak and has high biological effectiveness. Locally advanced head and neck cancer has been treated with C-ion RT at the National Institute of Radiological Sciences (NIRS) (Chiba, Japan) since 1994 (5). At NIRS, C-ion RT has shown excellent outcomes with BSS-HN, with 3-year local control (LC) rate of $91.8 \%$ and OS of $74.1 \%$ (6). However, this NIRS report (6) originated from a single institution, necessitating reproducibility at other facilities. Therefore, we conducted a prospective study to confirm the efficacy and safety of an established dose and fractionation schedule of C-ion RT for BSS-HN. 


\section{Patients and Methods}

Patients. The present study was a prospective clinical study that included 10 consecutive patients diagnosed with inoperable BSS-HN treated with C-ion RT between June 2012 and May 2018 at Gunma University Heavy Ion Medical Center. This study was approved by our Institutional Review Board (trial approval number: 921, trial registration number: UMIN000007938) and carried out in accordance with the Declaration of Helsinki. The target number of patients for this study was 15; however, poor accrual due to the rarity of BSS-HN resulted in only 10 patients being enrolled over a 6-year period. All patients provided informed consent prior to treatment. The inclusion criteria were as follows: (i) Histologically confirmed bone and softtissue sarcoma, (ii) N0-1 M0 disease, (iii) measurable tumor, (iv) age 16-80 years, and (v) performance status $0-2$. The exclusion criteria were as follows: (i) History of irradiation of the head and neck, (ii) history of chemotherapy within 4 weeks before C-ion RT, (iii) uncontrolled infection, (iv) severe concomitant disease, and (v) active double cancer. All biopsy specimens were centrally re-evaluated by a pathologist at Gunma University Hospital (Maebashi, Japan). Evaluations included physical examination, laryngoscopy, computed tomography (CT), magnetic resonance imaging (MRI), and ${ }^{18} \mathrm{~F}$ fluorodeoxyglucose positron-emission tomography/computed tomography (FDG PET/CT) within 1 month before treatment to rule out distant metastasis. The primary endpoint was the 3-year LC rate; LC was defined as no evidence of tumor regrowth in the planning target volume (PTV). Secondary endpoints were the 3-year OS rate, the progression-free survival (PFS) rate, and adverse events. Acute and late adverse events were evaluated according to the Common Terminology Criteria for Adverse Events version 4.0. (ver. 4.0) (7).

None of the patients in this series received concomitant systemic treatments. Table I summarizes the patient and tumor characteristics. The primary tumor sites were the maxillary sinus $(\mathrm{n}=3)$, nasal cavity $(\mathrm{n}=2)$, maxilla $(\mathrm{n}=2)$, oral cavity $(\mathrm{n}=2)$, and pterygopalatine fossa $(\mathrm{n}=1)$.

C-Ion RT. In this study, we used the C-ion RT techniques and treatment plans as were previously reported $(8,9)$. Briefly, patients were immobilized using thermoplastic shells (Shellfitter; Kuraray, Osaka, Japan) and positioned in customized cradles (Moldcare; Alcare, Tokyo, Japan). A customized mouthpiece maintained the position of the lower jaw (10). CT simulation (thickness, $2 \mathrm{~mm}$ ) was performed for treatment planning and MRI for reference imaging. The XiO-N system (Elekta, Stockholm, Sweden) was used for treatment planning. Delineation of the gross tumor volume (GTV) was based on contrast-enhanced MRI. The clinical target volume (CTV) had at least a 5-mm margin around the GTV. CTV1 included all anatomic sites where the tumors were located, whereas CTV2 was limited to around the GTV. PTV1 and PTV2 had 2-mm margins around CTV1 and CTV2, respectively. The CTV and PTV margins were modified as necessary when the targets were close to the organs at risk. The radiation dose was prescribed at the isocenter of the PTVs. The PTVs were encompassed by the $95 \%$ isodose line of the prescribed dose. Physical dose calculations were performed using the pencil-beam algorithm. The clinical dose distribution was calculated using the physical dose and relative biological effectiveness (RBE) obtained from the responses of human salivary gland tumor cells. The C-ion RT dose was expressed as Gy (RBE) (11). Doses were delivered over 16 fractions, and the overall treatment time was approximately 4 weeks (4 fractions per week). All patients received $70.4 \mathrm{~Gy}$ (RBE) in 16 fractions according to the clinical protocol.
Table I. Patient and tumor characteristics.

\begin{tabular}{|c|c|}
\hline Characteristic & \\
\hline \multicolumn{2}{|l|}{ Age, years } \\
\hline Mean (range) & $51.5(19-79)$ \\
\hline \multicolumn{2}{|l|}{ Gender, $\mathrm{n}$} \\
\hline Male & 5 \\
\hline Female & 5 \\
\hline \multicolumn{2}{|l|}{ Histological type, $\mathrm{n}$} \\
\hline Chondrosarcoma & 2 \\
\hline Undifferentiated pleomorphic sarcoma & 2 \\
\hline Liposarcoma & 1 \\
\hline Angiosarcoma & 1 \\
\hline Malignant pleomorphic and spindle cell tumor & 1 \\
\hline Malignant peripheral nerve sheath tumor & 1 \\
\hline Rhabdomyosarcoma & 1 \\
\hline Ameloblastic fibrosarcoma & 1 \\
\hline \multicolumn{2}{|l|}{ Region, $\mathrm{n}$} \\
\hline Maxillary sinus & 3 \\
\hline Nasal cavity & 2 \\
\hline Maxilla & 2 \\
\hline Oral cavity & 2 \\
\hline Pterygopalatine fossa & 1 \\
\hline \multicolumn{2}{|l|}{ Initial treatment } \\
\hline Surgery & 3 \\
\hline None & 7 \\
\hline \multicolumn{2}{|l|}{ GTV, cc } \\
\hline Mean (range) & $66(6-276)$ \\
\hline$>66 \mathrm{cc}, \mathrm{n}$ & 6 \\
\hline$\leq 66 \mathrm{cc}, \mathrm{n}$ & 4 \\
\hline \multicolumn{2}{|l|}{ Total dose, $\mathrm{n}$} \\
\hline 70.4 Gy(RBE) & 10 \\
\hline
\end{tabular}

GTV: Gross tumor volume; RBE: relative biological effectiveness.

Follow-up. Patients were followed-up every month for the first 6 months and every 3 months thereafter. CT and MRI were performed alternately every 3 months and FDG PET/CT, every year. LC was monitored until death, and patients were not censored despite the development of lymph node or distant metastasis.

Statistical analysis. LC, OS, and PFS rates were estimated using the Kaplan-Meier method and compared using log-rank tests. Differences between groups were assessed using $t$-tests. Differences were considered statistically significant at $p<0.05$. Statistical analyses were performed using IBM SPSS Statistics (version 26.0; IBM, Armonk, NY, USA).

\section{Results}

Between June 2012 and May 2018, 10 patients with inoperable bone and soft-tissue sarcoma prospectively underwent C-ion RT at Gunma University Heavy Ion Medical Center. Patient characteristics are summarized in Table I, and a representative case is shown in Figure 1. The median follow-up time for the whole patient cohort was 33.5 (range=16.7-81.8) months. There were two chondrosarcomas, two undifferentiated pleomorphic sarcomas, and six other pathologies. None of the patients had lymph node metastasis. 

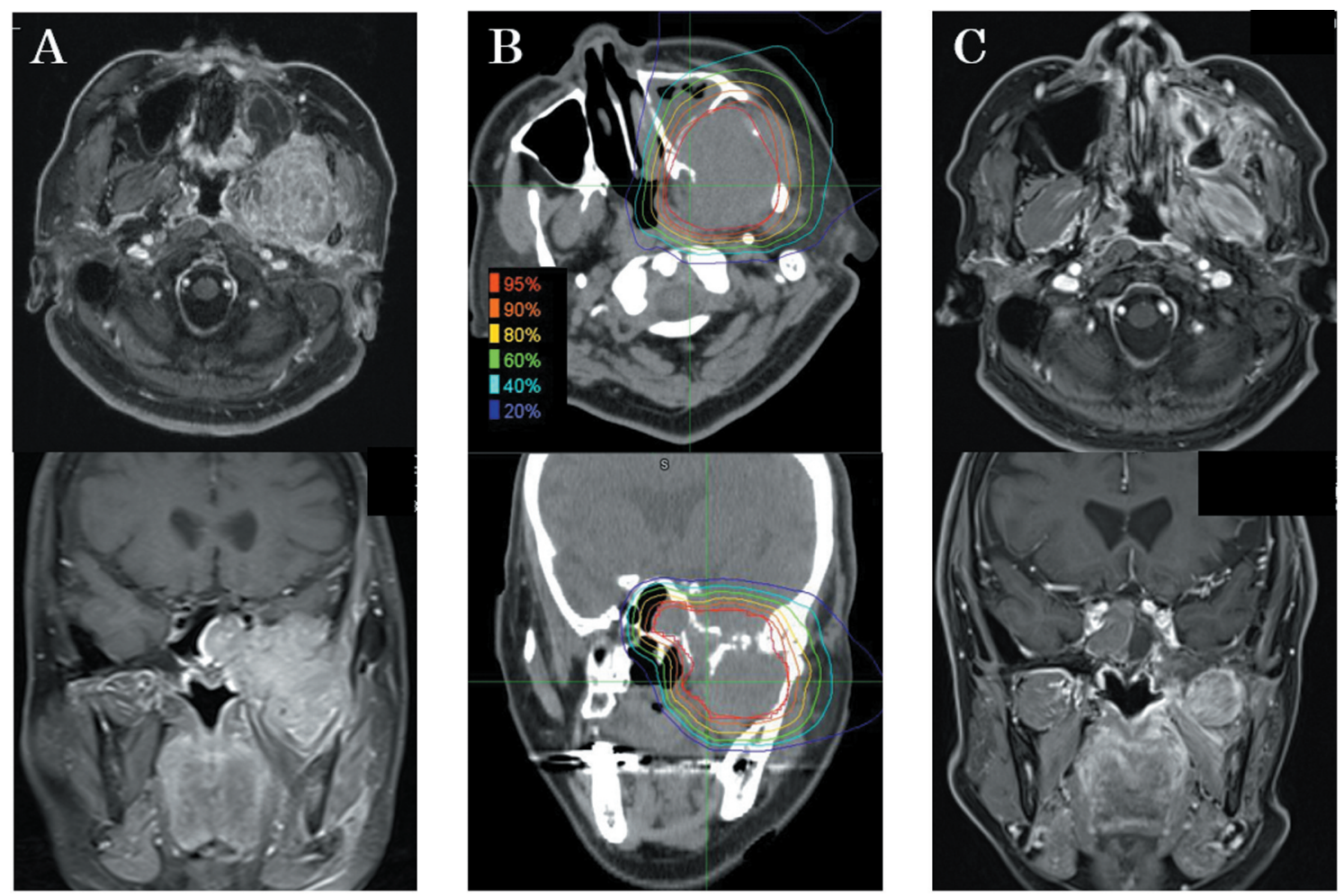

Figure 1. Representative case of undifferentiated pleomorphic sarcoma of the pterygopalatine fossa treated with carbon-ion radiotherapy (C-ion $R T$ ). A 60-year-old female patient had tumor invasion of the pterygopalatine fossa. A: Contrast-enhanced T1-weighted magnetic resonance imaging revealed the area around the pterygopalatine fossa. The patient was diagnosed with inoperable bone and soft-tissue sarcomas of the head and neck and treated with C-ion RT. B: Dose distribution of C-ion RT using $70.4 \mathrm{~Gy}$ (relative biological effectiveness) in 16 fractions. The gross tumor volume is shown in red. C: Twenty-four months after treatment, magnetic resonance imaging showed the tumor had shrunk. The patient has grade 2 trismus and is still alive more than 3 years after treatment. The patient additionally underwent surgery for recurrence of the lymph node at the neck 28 months later.

Follow-up after C-ion RT for all 10 patients is summarized in Table II. During follow-up, two patients had local recurrence in the maxilla $(\mathrm{n}=1)$ and oral cavity $(\mathrm{n}=1)$; salvage surgery was performed on these patients, and they survived without disease progression or severe postoperative complications at the last follow-up (16.8 and 62.5 months, respectively, after surgery). The 3-year LC rate was $72.9 \%$ [95\% confidence interval $(C I)=35.1-62.0 \%]$ (Figure 2). The 1-year LC rate was $100 \%$, regardless of the size of the GTV $(n=10)$ (Figure 2 and Table II). The mean GTV was $66 \mathrm{cc}$ (Table I). There was no significant difference between the 3-year LC rates for those with GTV $\leq 66 \mathrm{cc}$ and GTV $>66 \mathrm{cc}$, which were $100 \%$ and $53.3 \%$, respectively (Figure $3 \mathrm{~A} ; p=0.209$ ).

One patient died of disease progression and one of intercurrent disease (renal failure). The 3-year OS rate was $77.8 \%$ (95\% CI=50.8-84.8\%) (Figure 4). There was no significant difference between the 3-year OS rates for patients with GTV $\leq 66 \mathrm{cc}$ and those with GTV $>66 \mathrm{cc}$, which were $100 \%$ and $66.7 \%$, respectively (Figure 3B, $p=0.259$ ). During follow-up, six patients had disease progression; the 3-year PFS for the whole cohort was 36\% (95\% CI=14.8-45.1\%) (Figure 4). There was no significant difference between the 3-year PFS rates for those with GTV $\leq 66 \mathrm{cc}$ and GTV $>66 \mathrm{cc}$, which were $50 \%$ and $22.2 \%$, respectively (Figure 3C, $p=0.884$ ). The first site of progressive disease was local disease in two patients, lymph node metastasis in three, and distant metastasis in three (bone in one, lung in two, multiple sites in one).

Acute and late adverse events are shown in Table III. Acute grade 2-3 mucositis and dermatitis were the most common adverse events, which improved immediately after conservative therapy. Grade 3 chronic mucositis was observed in one patient, who required analgesia. Grade 3 trismus was observed in one patient, who required gastrostoma because the tumor invaded almost all the muscles of mastication. There were three cases of grade 3 osteoradionecrosis that required analgesia and hyperbaric oxygen therapy, and these tumors had a tendency for widespread invasion of the maxilla and mandible. There was a case of grade 3 olfactory nerve disorder and a case of grade 
Table II. Patient characteristics and therapeutic outcomes.

\begin{tabular}{|c|c|c|c|c|c|c|c|c|c|c|}
\hline $\begin{array}{l}\text { Patient } \\
\text { no. }\end{array}$ & $\begin{array}{l}\text { Age, } \\
\text { years }\end{array}$ & Gender & $\begin{array}{l}\text { Histological } \\
\text { type }\end{array}$ & Region & $\begin{array}{l}\text { Initial } \\
\text { treatment }\end{array}$ & $\begin{array}{l}\text { GTV, } \\
\mathrm{cc}\end{array}$ & $\begin{array}{l}\text { Local } \\
\text { recurrence }\end{array}$ & $\begin{array}{l}\text { Distant } \\
\text { metastasis }\end{array}$ & $\begin{array}{l}\text { Additional } \\
\text { treatment* }\end{array}$ & $\begin{array}{l}\text { Status at } \\
\text { study end }\end{array}$ \\
\hline 1 & 48 & Male & Liposarcoma & Oral cavity & Surgery & 12.07 & No & & & Alive \\
\hline 2 & 58 & Male & Chondrosarcoma & Maxilla & None & 124.05 & Yes & & Salvage surgery & Dead \\
\hline 3 & 79 & Female & $\begin{array}{c}\text { Undifferentiated } \\
\text { pleomorphic sarcoma }\end{array}$ & $\begin{array}{l}\text { Maxillary } \\
\text { sinus }\end{array}$ & None & 67.67 & No & Lung & None & Dead \\
\hline 4 & 24 & Male & $\begin{array}{l}\text { Malignant pleomorphic } \\
\text { and spindle cell tumor }\end{array}$ & Oral cavity & $\begin{array}{c}\text { Chemotherapy } \\
\text { (HD-MTX, } \\
\text { CDDP, ADR) }\end{array}$ & 225.82 & Yes & $\begin{array}{c}\text { Axillary } \\
\text { lymph node }\end{array}$ & None & Alive \\
\hline 5 & 19 & Male & Rhabdomyosarcoma & Nasal cavity & None & 53.59 & No & Bone & $\begin{array}{l}\text { Radiotherapy, } \\
\text { VAC }\end{array}$ & Alive \\
\hline 6 & 44 & Female & Angiosarcoma & Maxillary sinus & None & 62.09 & No & Lung & $\begin{array}{l}\text { Chemotherapy } \\
\text { (PTX) }\end{array}$ & Alive \\
\hline 7 & 27 & Male & $\begin{array}{l}\text { Malignant peripheral } \\
\text { nerve sheath tumor }\end{array}$ & Maxillary sinus & None & 276.31 & No & & & Alive \\
\hline 8 & 55 & Female & Chondrosarcoma & Nasal cavity & Surgery & 5.63 & No & & & Alive \\
\hline 9 & 60 & Female & $\begin{array}{c}\text { Undifferentiated } \\
\text { pleomorphic sarcoma }\end{array}$ & $\begin{array}{l}\text { Pterygopalatine } \\
\text { fossa }\end{array}$ & None & 90.35 & No & $\begin{array}{l}\text { Cervical } \\
\text { lymph node }\end{array}$ & $\begin{array}{l}\text { Salvage } \\
\text { surgery }\end{array}$ & Alive \\
\hline 10 & 68 & Female & $\begin{array}{l}\text { Ameloblastic } \\
\text { fibrosarcoma }\end{array}$ & Maxilla & None & 70.63 & No & & & Dead \\
\hline
\end{tabular}

ADR: Adriamycin; CDDP: cisplatin; HD-MX: High-dose methotrexate; PTX: paclitaxel; VAC: vincristine, actinomycin D and cyclophosphamide. *After local recurrence/distant metastasis.

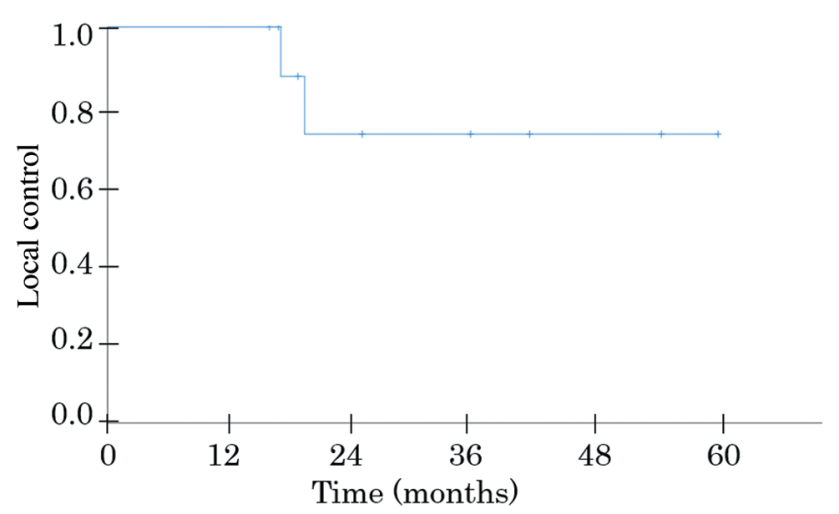

Figure 2. Local control curve for bone and soft-tissue sarcoma treated with carbon-ion radiotherapy. The 3-year local control rate for patients overall ( $n=10)$ was $72.9 \%$.

3 middle ear infection. There was a case of grade 4 visual impairment (optic nerve disorder) in which the tumor invaded the orbital space and was close to the eye.

\section{Discussion}

The present study analyzed a prospective clinical study of patients diagnosed with inoperable BSS-HN and treated with C-ion RT. Previous historical results of C-ion RT with a total dose of 57.6 or 64 Gy (RBE) from NIRS showed 3-year LC and OS rates of $23.6 \%$ and $42.9 \%$, respectively (5). However, when
Table III. Acute and late adverse events for all patients $(n=10)$.

\begin{tabular}{|c|c|c|c|c|c|c|}
\hline & & \multicolumn{5}{|c|}{ Grade, $\mathrm{n}$} \\
\hline \multicolumn{2}{|c|}{ Adverse event } & 0 & 1 & 2 & 3 & 4 \\
\hline \multirow[t]{5}{*}{ Acute } & Mucositis & 0 & 1 & 3 & 4 & 0 \\
\hline & Dermatitis & 0 & 2 & 6 & 2 & 0 \\
\hline & Xerostomia & 7 & 2 & 1 & 0 & 0 \\
\hline & Dysgeusia & 8 & 2 & 0 & 0 & 0 \\
\hline & Conjunctivitis & 8 & 1 & 1 & 0 & 0 \\
\hline \multirow[t]{16}{*}{ Late } & Mucositis & 7 & 2 & 0 & 1 & 0 \\
\hline & Dermatitis & 2 & 7 & 0 & 1 & 0 \\
\hline & Xerostomia & 8 & 2 & 0 & 0 & 0 \\
\hline & Dysgeusia & 7 & 2 & 1 & 0 & 0 \\
\hline & Conjunctivitis & 8 & 2 & 0 & 0 & 0 \\
\hline & Trismus & 4 & 2 & 3 & 1 & 0 \\
\hline & Osteoradionecrosis & 6 & 1 & 0 & 3 & 0 \\
\hline & Brain necrosis & 8 & 2 & 0 & 0 & 0 \\
\hline & Brainstem necrosis & 10 & 0 & 0 & 0 & 0 \\
\hline & Nasal congestion & 7 & 3 & 1 & 0 & 0 \\
\hline & Chronic sinusitis & 9 & 0 & 1 & 0 & 0 \\
\hline & Olfactory nerve disorder & 8 & 1 & 0 & 1 & 0 \\
\hline & Middle-ear infection & 8 & 0 & 1 & 1 & 0 \\
\hline & External otitis & 9 & 0 & 1 & 0 & 0 \\
\hline & Cataract & 10 & 0 & 0 & 0 & 0 \\
\hline & Optic nerve disorder & 9 & 0 & 0 & 0 & 1 \\
\hline
\end{tabular}

the total dose was increased to 70.4 Gy (RBE), the 3-year LC and OS rates improved to $91.8 \%$ and $74.1 \%$, respectively (6). In this study, we used a total dose of $70.4 \mathrm{~Gy}$ (RBE), and the 3-year LC and OS rates were $72.9 \%$ and $77.8 \%$, respectively. 

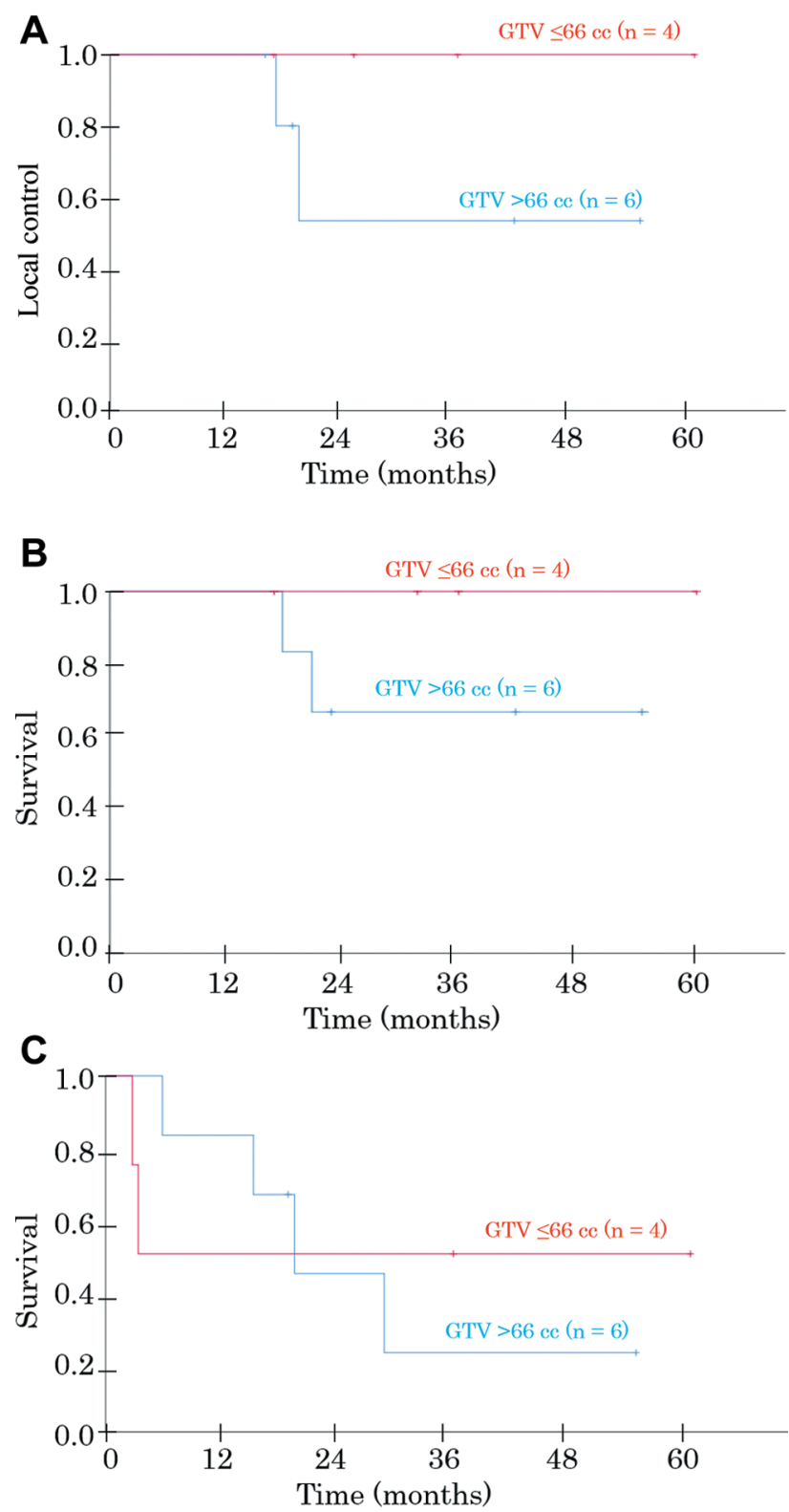

Figure 3. A: Local control curve for bone and soft-tissue sarcoma treated with carbon-ion radiotherapy. The 3-year local control rates for gross tumor volume $(G T V) \leq 66 \mathrm{cc}$ and GTV $>66 \mathrm{cc}$ were $100 \%$ and $53.3 \%$, respectively $(p=0.209)$. B: Overall survival (OS) curves for patients with bone and soft-tissue sarcoma treated with carbon-ion radiotherapy according to GTV. The 3-year OS rates for patients with GTV $\leq 66 c c$ and $G T V>66 c c$ were $100 \%$ and $66.7 \%$, respectively $(p=0.295)$. C: The 3-year PFS rates for those with GTV $\leq 66 c c$ and GTV $>66 c c$ were $50 \%$ and $22.2 \%$, respectively $(p=0.884)$.

The results of the present study were similar to those of the previous NIRS study on treatment outcomes (6), although the LC of our study was slightly inferior (6). Therefore, the effect of C-ion RT on inoperable BSS-HN was reproduced (Table IV).

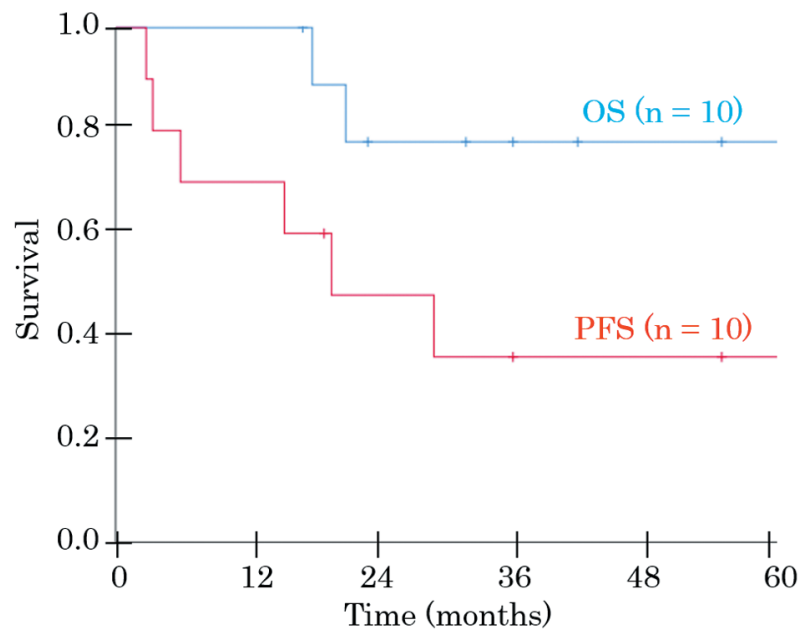

Figure 4. Overall (OS) and progression-free (PFS) survival curves for patients with bone and soft-tissue sarcoma treated with carbon-ion radiotherapy. The 3-year $O S$ and PFS rates for patients overall $(n=10)$ were $77.8 \%$ and $36 \%$, respectively.

The standard treatment guidelines for BSS-HN are radical surgery, neoadjuvant and adjuvant chemotherapy, and radiotherapy. However, the literature shows the prognosis for BSS-HN was poor, with a 5-year LC rate of 21.0-47.0\% with surgery, chemotherapy, and radiotherapy $(2,4)$ (Table IV). Moreover, the 5-year OS rates were $21.7 \%$ and $36 \%$ for those treated with chemotherapy and radiotherapy, and $50 \%$ and $59.7 \%$ for those treated with surgery, chemotherapy, and radiotherapy, respectively $(2,4)$ (Table IV). For bone and soft-tissue sarcomas located in regions other than the head and neck treated with C-ion RT, the GTV was considered a significant prognostic factor for OS and LC (12-14), and a previous study also reported that a GTV higher than $100 \mathrm{cc}$ is a significant factor associated with worse OS for BSS-HN treated with C-ion RT (6). However, the GTV was not significantly correlated with OS, PFS, or LC in the present study. Another recent treatment study reported on craniofacial osteosarcoma treated with protons and a $\mathrm{C}$-ion boost. This study reported 2-year PFS and OS rates of $45 \%$ and $68 \%$, respectively (15) (Table IV). Most adverse events were grade 2 or lower, and the reasonably high OS suggests particle beam therapy (carbon and proton) for BSS-HN might be a possibility in the future. However, despite the proton and $\mathrm{C}$-ion boost intervention, the $\mathrm{OS}$ in the previous study (15) was slightly lower than that of our study. Lower OS might be related to lower LC and PFS. It may be important to irradiate the target with a high dose of C-ions, which has excellent biological effects for BSS-HN.

In the present study, acute adverse events improved immediately; however, a few late adverse events, such as 
Table IV. Comparing outcomes for bone and soft-tissue sarcomas of head and neck by treatment modality.

\begin{tabular}{|c|c|c|c|c|c|c|}
\hline \multirow[b]{2}{*}{ Author (Ref) } & \multirow[b]{2}{*}{ Treatment strategy } & \multicolumn{5}{|c|}{ Endpoint } \\
\hline & & $\begin{array}{l}\text { Number of } \\
\text { patients }\end{array}$ & $\begin{array}{l}\text { Time } \\
\text { point }\end{array}$ & $\begin{array}{l}\text { Local } \\
\text { control }\end{array}$ & $\begin{array}{l}\text { Overall } \\
\text { survival }\end{array}$ & $\begin{array}{l}\text { Mean follow-up, } \\
\text { months }\end{array}$ \\
\hline \multirow[t]{2}{*}{ Eeles et al. (2) } & Surgery \pm radiotherapy \pm chemotherapy & 103 & 5-Year: & $47.0 \%$ & $50.0 \%$ & \multirow[t]{2}{*}{50.0} \\
\hline & Radiotherapy \pm chemotherapy & 17 & 5-Year: & $21.0 \%$ & $36.0 \%$ & \\
\hline Kepka et al. (3) & Surgery \pm radiotherapy \pm chemotherapy & 112 & 5-Year: & $45.0 \%$ & $35.0 \%$ & 139.0 \\
\hline \multirow{2}{*}{ Smith et al. (4) } & Surgery \pm radiotherapy \pm chemotherapy & 496 & - & - & $59.7 \%$ & - \\
\hline & Radiotherapy \pm chemotherapy & 71 & - & - & $21.7 \%$ & - \\
\hline Mizoe et al. (5) & $\begin{array}{l}\text { Carbon-ion radiotherapy } \\
57.6 \text { or } 64 \mathrm{~Gy}(\mathrm{RBE}) / 16 \mathrm{fr}\end{array}$ & 14 & 3-Year: & $23.6 \%$ & $42.9 \%$ & 54.0 \\
\hline Jingu et al. (6) & $\begin{array}{l}\text { Carbon-ion radiotherapy } \\
70.4 \mathrm{~Gy}(\mathrm{RBE}) / 16 \mathrm{fr}\end{array}$ & 27 & $\begin{array}{l}\text { 3-Year: } \\
\text { 5-Year: }\end{array}$ & $\begin{array}{l}91.8 \% \\
80.4 \%\end{array}$ & $\begin{array}{l}74.1 \% \\
57.6 \%\end{array}$ & 37.0 \\
\hline Seidensaal et al. (13) & $\begin{array}{l}\text { Proton radiotherapy } 54 \mathrm{~Gy}(\mathrm{RBE}) / 27 \mathrm{fr} \\
+ \text { Carbon-ion radiotherapy } \\
18 \mathrm{~Gy}(\mathrm{RBE}) / 6 \mathrm{fr}\end{array}$ & 18 & $\begin{array}{l}\text { 1-Year: } \\
\text { 2-Year: }\end{array}$ & $\begin{array}{l}- \\
-\end{array}$ & $\begin{array}{l}75.0 \% \\
68.0 \%\end{array}$ & 34.5 \\
\hline Current study & $\begin{array}{l}\text { Carbon-ion radiotherapy } \\
70.4 \text { Gy }(\mathrm{RBE}) / 16 \mathrm{fr}\end{array}$ & 10 & $\begin{array}{l}\text { 2-Year: } \\
\text { 3-Year: }\end{array}$ & $\begin{array}{l}72.9 \% \\
72.9 \%\end{array}$ & $\begin{array}{l}77.8 \% \\
72.9 \%\end{array}$ & 33.5 \\
\hline
\end{tabular}

Fr: Fractions; RBE: relative biological effectiveness.

trismus and osteoradionecrosis, were not alleviated by conservative therapy. The incidence of adverse events was generally comparable to the acute and late adverse events reported in a previous study (6). Late adverse events have a large impact on patients and should be prevented. However, because the grade 3 or higher late adverse events in this study were very close to each organ, it is the likely their onset could not be suppressed. Additionally, therapeutic Cion doses for bone and soft-tissue sarcomas are higher than those for other pathological types, such as non-squamous cell carcinoma and malignant melanoma. Because of the small number of cases in the present study, the relationship between the onset of adverse events and treatment outcomes is unclear; however, reducing acute adverse events, which should be achieved as far as possible, will also reduce late adverse events (16-18). Onset doses for adverse events such as oral mucositis (19) and dermatitis (20) from C-ion RT for the head and neck have been reported. According to these reports, preventing the onset of acute adverse events is essential. Furthermore, preventing acute adverse events can also reduce the occurrence of late adverse events (14-16). Late adverse events such as osteoradionecrosis $(21,22)$, trismus (23), nasolacrimal duct obstruction (24), tooth loss (25), brainstem necrosis (26), brain injury (27), and optic nerve injury (28) have been reported. In the future, we intend to develop a C-ion RT plan considering these dose indicators of onset; thus, the incidence of adverse events is anticipated to be reduced compared with that of the present study.

This study had a few limitations. Firstly, it involved patients enrolled at a single institution. There are few institutes that administer C-ion RT; future prospective studies should increase the number of patients enrolled and include more institutes. Secondly, bone and soft-tissue sarcomas have various pathological types. Because the therapeutic effect of C-ion RT depends on the pathological tissue type, further research is important.

In conclusion, the present study reproduced the effect of C-ion RT on inoperable BSS-HN. Adverse events were also within the expected range, but the dose to organs at risk should be considered for further mitigation of adverse events.

\section{Conflicts of Interest}

None to be declared.

\section{Authors' Contributions}

Conceived and designed the research: AM, KS and JS; performed the research, analyzed the data, and contributed materials/analysis tools: AM, NK, HK, NaokoOkano, HS, KO, Naoto Osu, HY, AA and TO; planned the treatment: AM, NK, HK, Naoko Okano, KS, JS and TO; analyzed the treatment and contributed to the final draft of the article: AM, NK, HK, Naoko Okano, HS, KO, Naoto Osu, HY, AA and TO; All Authors read and approved the final article: AM, NK, HK, Naoko Okano, HS, KO, Naoto Osu, HY, AA, YT, MS, ON, SI, KS, JS, SY, KC and TO.

\section{Acknowledgements}

The Authors thank Editage (www.editage.jp) for English language editing. This work was supported by JSPS KAKENHI (Grant Number 21K07693), the Uehara Memorial Foundation, and the Takeda Science Foundation. 


\section{References}

1 Farhood AI, Hajdu SI, Shiu MH and Strong EW: Soft tissue sarcomas of the head and neck in adults. Am J Surg 160(4): 365369, 1990. PMID: 2221235. DOI: 10.1016/s0002-9610(05)80544-6

2 Eeles RA, Fisher C, A'Hern RP, Robinson M, Rhys-Evans P, Henk JM, Archer D and Harmer CL: Head and neck sarcomas: prognostic factors and implications for treatment. Br J Cancer 68(1): 201-207, 1993. PMID: 8318414. DOI: $10.1038 /$ bjc.1993.314

3 Kepka L, DeLaney TF, Suit HD and Goldberg SI: Results of radiation therapy for unresected soft-tissue sarcomas. Int J Radiat Oncol Biol Phys 63(3): 852-859, 2005. PMID: 16199316. DOI: 10.1016/j.ijrobp.2005.03.004

4 Smith RB, Apostolakis LW, Karnell LH, Koch BB, Robinson RA, Zhen W, Menck HR and Hoffman HT: National Cancer Data Base report on osteosarcoma of the head and neck. Cancer 98(8): 16701680, 2003. PMID: 14534884. DOI: $10.1002 /$ cncr.11716

5 Mizoe JE, Hasegawa A, Jingu K, Takagi R, Bessyo H, Morikawa T, Tonoki M, Tsuji H, Kamada T, Tsujii H, Okamoto Y and Organizing Committee for the Working Group for Head Neck Cancer: Results of carbon ion radiotherapy for head and neck cancer. Radiother Oncol 103(1): 32-37, 2012. PMID: 22321201. DOI: $10.1016 /$ j.radonc.2011.12.013

6 Jingu K, Tsujii H, Mizoe JE, Hasegawa A, Bessho H, Takagi R, Morikawa T, Tonogi M, Tsuji H, Kamada T, Yamada S and Organizing Committee for the Working Group for Head-and-Neck Cancer: Carbon ion radiation therapy improves the prognosis of unresectable adult bone and soft-tissue sarcoma of the head and neck. Int J Radiat Oncol Biol Phys 82(5): 2125-2131, 2012. PMID: 21745719. DOI: 10.1016/j.ijrobp.2010.08.043

7 National Cancer Institute Common Terminology Criteria for Adverse Events (CTCAE) v.4.03. Available at: http:// evs.nci.nih.gov/ftp1/CTCAE/About.html [Last accessed on November 26, 2020]

8 Shirai K, Saitoh JI, Musha A, Abe T, Kobayashi D, Takahashi T, Tamaki T, Kawamura H, Takayasu Y, Shino M, Toyoda M, Takahashi K, Hirato J, Yokoo S, Chikamatsu K, Ohno T, Nakano $\mathrm{T}$ and Working Group on Head and Neck Tumors: Prospective observational study of carbon-ion radiotherapy for non-squamous cell carcinoma of the head and neck. Cancer Sci 108(10): 20392044, 2017. PMID: 28730646. DOI: 10.1111/cas.13325

9 Musha A, Kubo N, Okano N, Kaminuma T, Kawamura H, Sato H, Takayasu Y, Shino M, Nikkuni O, Ida S, Shirai K, Saitoh J, Ogawa M, Yokoo S, Chikamatsu K and Ohno T: Prospective observational study of carbon-ion radiotherapy for non-squamous cell carcinoma of the head and neck in Gunma University. Journal of Oral and Maxillofacial Surgery, Medicine, and Pathology, 2021. DOI: 10.1016/j.ajoms.2021.10.012

10 Musha A, Saitoh J, Shirai K, Kubota Y, Shimada H, Abe T, Komatsu Y, Komatsu S, Ohno T, Nakano $\mathrm{T}$ and Yokoo S: Customized mouthpieces designed to reduce tongue mucositis in carbon-ion radiotherapy for tumors of the nasal and paranasal sinuses. Physics and Imaging in Radiation Oncology 3: 1-4, 2019. DOI: $10.1016 /$ j.phro.2017.07.003

11 Kanai T, Endo M, Minohara S, Miyahara N, Koyama-ito H, Tomura H, Matsufuji N, Futami Y, Fukumura A, Hiraoka T, Furusawa Y, Ando K, Suzuki M, Soga F and Kawachi K: Biophysical characteristics of HIMAC clinical irradiation system for heavy-ion radiation therapy. Int J Radiat Oncol Biol Phys 44(1): 201-210, 1999. PMID: 10219815. DOI: 10.1016/s0360-3016(98)00544-6
12 Shiba S, Okamoto M, Kiyohara H, Okazaki S, Kaminuma T, Shibuya K, Kohama I, Saito K, Yanagawa T, Chikuda H, Nakano $\mathrm{T}$ and Ohno $\mathrm{T}$ : Impact of carbon ion radiotherapy on inoperable bone sarcoma. Cancers (Basel) 13(5): 1099, 2021. PMID: 33806515. DOI: 10.3390/cancers 13051099

13 Imai R, Kamada T, Araki N and Working Group for Bone and Soft-Tissue Sarcomas: Clinical efficacy of carbon ion radiotherapy for unresectable chondrosarcomas. Anticancer Res 37(12): 69596964, 2017. PMID: 29187480. DOI: 10.21873/anticanres.12162

14 Cuccia F, Fiore MR, Barcellini A, Iannalfi A, Vischioni B, Ronchi S, Bonora M, Riva G, Vai A, Facoetti A, Preda L, Valvo F and Vitolo V: Outcome and toxicity of carbon ion radiotherapy for axial bone and soft tissue sarcomas. Anticancer Res 40(5): 2853-2859, 2020. PMID: 32366434. DOI: 10.21873/anticanres.14260

15 Seidensaal K, Mattke M, Haufe S, Rathke H, Haberkorn U, Bougatf N, Kudak A, Blattmann C, Oertel S, Kirchner M, Buesch C, Kieser M, Herfarth K, Kulozik A, Debus J, Uhl M and Harrabi $\mathrm{SB}$ : The role of combined ion-beam radiotherapy (CIBRT) with protons and carbon ions in a multimodal treatment strategy of inoperable osteosarcoma. Radiother Oncol 159: 8-16, 2021. PMID: 33549644. DOI: 10.1016/j.radonc.2021.01.029

16 Denham JW, Peters LJ, Johansen J, Poulsen M, Lamb DS, Hindley A, O'Brien PC, Spry NA, Penniment M, Krawitz H, Williamson $\mathrm{S}$, Bear $\mathrm{J}$ and Tripcony L: Do acute mucosal reactions lead to consequential late reactions in patients with head and neck cancer? Radiother Oncol 52(2): 157-164, 1999. PMID: 10577701. DOI: 10.1016/s0167-8140(99)00107-3

17 Bentzen SM and Trotti A: Evaluation of early and late toxicities in chemoradiation trials. J Clin Oncol 25(26): 4096-4103, 2007. PMID: 17827459. DOI: 10.1200/JCO.2007.13.3983

18 Dörr W and Hendry JH: Consequential late effects in normal tissues. Radiother Oncol 61(3): 223-231, 2001. PMID: 11730991. DOI: $10.1016 / \mathrm{s} 0167-8140(01) 00429-7$

19 Musha A, Shimada H, Shirai K, Saitoh J, Yokoo S, Chikamatsu K, Ohno $\mathrm{T}$ and Nakano T: Prediction of acute radiation mucositis using an oral mucosal dose surface model in carbon ion radiotherapy for head and neck tumors. PLoS One 10(10): e0141734, 2015. PMID: 26512725. DOI: 10.1371/journal.pone. 0141734

20 Kubo N, Kubota Y, Oike T, Kawamura H, Sakai M, Imamura A, Komatsu S, Miyasaka Y, Sato H, Musha A, Okano N, Shirai K, Saitoh JI, Chikamatsu K and Ohno T: Skin dose reduction by layer-stacking irradiation in carbon ion radiotherapy for parotid tumors. Front Oncol 10: 1396, 2020. PMID: 32923391. DOI: 10.3389/fonc.2020.01396

21 Musha A, Shimada H, Kubo N, Kawamura H, Okano N, Sato H, Kaminuma T, Okada K, Anakura M, Adachi A, Shirai K, Saitoh JI, Yokoo S, Chikamatsu K and Ohno T: Clinical features and dosimetric evaluation of carbon ion radiation-induced osteoradionecrosis of mandible in head and neck tumors. Radiother Oncol 161: 205-210, 2021. PMID: 34147522. DOI: 10.1016/ j.radonc.2021.06.022

22 Sasahara G, Koto M, Ikawa H, Hasegawa A, Takagi R, Okamoto $\mathrm{Y}$ and Kamada T: Effects of the dose-volume relationship on and risk factors for maxillary osteoradionecrosis after carbon ion radiotherapy. Radiat Oncol 9(1): 92, 2014. PMID: 24708583. DOI: 10.1186/1748-717X-9-92

23 Musha A, Shimada H, Kubo N, Kawamura H, Okano N, Miyasaka Y, Sato H, Shirai K, Saitoh JI, Yokoo S, Chikamatsu K and Ohno $\mathrm{T}$ : Evaluation of carbon ion radiation-induced trismus in head and 
neck tumors using dose-volume histograms. Cancers (Basel) 12(11): 3116, 2020. PMID: 33113829. DOI: 10.3390/cancers 12113116

24 Kubo N, Kubota Y, Kawamura H, Oike T, Sakai M, Kumazawa T, Miyasaka Y, Okazaki S, Kobayashi D, Sato H, Mizukami T, Musha A, Shirai K, Saitoh JI, Yokoo S, Chikamatsu K, Ohno T and Nakano T: Dosimetric parameters predictive of nasolacrimal duct obstruction after carbon-ion radiotherapy for head and neck carcinoma. Radiother Oncol 141: 72-77, 2019. PMID: 31439449. DOI: 10.1016/j.radonc.2019.07.022

25 Kubo N, Sakai M, Kawamura H, Oike T, Kubota Y, Anakura M, Adachi A, Sato H, Musha A, Okano N, Kaminuma T, Shirai K, Saitoh J, Yokoo S, Chikamatsu K and Ohno T: Dosimetric parameters predicting tooth loss after carbon ion radiotherapy for head and neck tumors. Radiation 1(3): 183-193, 2021. DOI: 10.3390/radiation 1030017

26 Shirai K, Fukata K, Adachi A, Saitoh JI, Musha A, Abe T, Kanai T, Kobayashi D, Shigeta Y, Yokoo S, Chikamatsu K, Ohno T and Nakano T: Dose-volume histogram analysis of brainstem necrosis in head and neck tumors treated using carbon-ion radiotherapy. Radiother Oncol 125(1): 36-40, 2017. PMID: 28867558. DOI: 10.1016/j.radonc.2017.08.014
27 Park S, Demizu Y, Suga M, Taniguchi S, Tanaka S, Maehata I, Takeda M, Takahashi D, Matsuo Y, Sulaiman NS, Terashima K, Tokumaru S, Furukawa K and Okimoto T: Predicted probabilities of brain injury after carbon ion radiotherapy for head and neck and skull base tumors in long-term survivors. Radiother Oncol 165: 152-158, 2021. PMID: 34718054. DOI: 10.1016/j.radonc.2021. 10.017

28 Hasegawa A, Mizoe JE, Mizota A and Tsujii H: Outcomes of visual acuity in carbon ion radiotherapy: analysis of dose-volume histograms and prognostic factors. Int J Radiat Oncol Biol Phys 64(2): 396-401, 2006. PMID: 16182466. DOI: 10.1016/j.ijrobp. 2005.07 .298
Received January 9, 2022

Revised January 20, 2022

Accepted January 26, 2022 